\title{
CC COBENGE \\ A tecnologia como ferramenta de adaptação do programa de educação tutorial em engenharia elétrica no contexto da pandemia de COVID-19.
}

\section{DOI: 10.37702/2175-957X.COBENGE.2021.3551}

Tiara Rodrigues Smarssaro de Freitas - tiara.freitas@ufes.br

UFES

Rua Odette de Oliveira Lacourt 1231

29060-050 - Vitória - ES

Thalis Rocha Pestana - rocha.thalis@gmail.com

Universidade Federal do Espírito Santo

Rua José Neves Cypreste 1091

29060-300 - Vitória - ES

Caio Henrique Rodrigues Marcelos - caio_marcelos@hotmail.com Universidade Federal do Espírito Santo

Rua Jahira Santos Rodrigues 20

29060-160 - Vitória - ES

Yuri Rissi Negri - yuri_rissi@hotmail.com

UFES

Rua Horto dos Alamos 295

29936-320 - São Mateus - ES

Kaique de Oliveira Barcellos - kaiquedeoliveirabarcellos@gmail.com IFES

Rua dos Morangos 06

29166-830 - Serra - ES

Arthur Sorrentino Ferreira - arthursorrentinoferreira@hotmail.com UFES

Rua São Marcos 287

29108-050 - Vila Velha - ES

Gabriel Falcone da Silva - gabrielfalconeee@gmail.com Universidade Federal do Espírito Santo

Rua dos Ipês 312 
29165-757 - Serra - ES

Matheus Penido Loureiro - mpenido07@gmail.com

UFES

Rua Topázio 26

29171-031 - Serra - ES

Resumo: Com o advento da pandemia de Covid-19, o isolamento social tornou-se regra, consequentemente, levando à suspensão das atividades letivas nas instituições de ensino. $O$ presente artigo teve como objetivo realizar uma análise dos impactos causados pela pandemia dentro do grupo PET Engenharia Elétrica da Universidade Federal do Espírito Santo e, principalmente, as adaptações adotadas pelos membros de forma a contornar essa situação com o auxílio da tecnologia. Para isso, foi elaborado um balanço dos projetos executados pelo PET Elétrica nos contextos pandêmico e pré-pandêmico, além da realização de uma coleta de dados com os membros do grupo de forma a conduzir um levantamento de caráter quali-quantitativo a respeito das mudanças adotadas. Em suma, os resultados deste levantamento foram apresentados e discutidos ao fim do artigo de forma a exibir os benefícios da tecnologia perante tal situação.

Palavras-chave: PET. Adaptação. Pandemia. Ensino remoto. Inovação. 


\section{A TECNOLOGIA COMO FERRAMENTA DE ADAPTAÇÃO DO PROGRAMA DE EDUCAÇÃO TUTORIAL EM ENGENHARIA ELÉTRICA NO CONTEXTO DA PANDEMIA DE COVID-19}

\section{INTRODUÇÃO}

As ferramentas digitais têm sido grandes aliadas na transmissão do conhecimento ao longo dos últimos anos, permitindo a extensão das capacidades de adquirir, organizar, armazenar, analisar, relacionar, integrar, aplicar e transmitir informação (CHAVES, 1999). Dessa forma, a tecnologia tem potencializado a propagação do conhecimento, possibilitando uma educação mais acessível.

De fato, essa realidade não é recente, é possível citar os programas Telecurso e Telecurso 2000, transmitidos na televisão desde o final da década de 1970 até o fim dos anos 1990, figurando como única fonte de conhecimento para uma parcela da população brasileira nesse período (SILVEIRA et al, 2010).

Mais recentemente, com a ascensão da Internet, a educação tem rompido as fronteiras físicas novamente. Dados apontam que, entre os anos de 2009 e 2019, o número de matrículas em cursos de ensino a distância (EaD) aumentou 378,9\% (INEP, 2020), demonstrando o crescente acesso à educação por intermédio dos recursos tecnológicos atuais.

Em março de 2020, decretos do governo do Espírito Santo estabeleceram estado de emergência e impuseram a suspensão das atividades presenciais nas instituições de ensino (ESPÍRITO SANTO, 2020). Cursos, escolas, faculdades e universidades se viram obrigados a adotar novas formas de ensino e inovarem na forma de transmitir e tornar 0 conhecimento acessível aos estudantes. Essa situação não foi diferente no caso da Universidade Federal do Espírito Santo (UFES) (UFES, 2020) e especialmente, o Programa de Educação Tutorial (PET) do curso de Engenharia Elétrica desta instituição.

Nesse preâmbulo, diante da urgência em dar prosseguimento aos trabalhos, dada a importância das atividades do PET na instituição e nas realidades em que atua, buscou-se alternativas para a continuidade dos projetos, descobrindo na tecnologia e na criatividade dos seus integrantes grandes aliadas para contornar os obstáculos impostos pela pandemia.

Este artigo apresenta um resumo sucinto sobre as mudanças organizacionais aplicadas para a adaptação do grupo ao contexto pandêmico, fundamentado no relato dos membros de cada subprojeto. Os relatos apresentam a organização dos subprojetos antes da interrupção das atividades presenciais, as mudanças implementadas e as dificuldades decorrentes do processo.

Objetiva-se o compartilhamento de informações pertinentes quanto à adaptação dos grupos PET, apresentando alguns exemplos que podem ser seguidos por outros grupos mesmo após a volta das atividades presenciais.

\section{O PET ELÉTRICA NO CONTEXTO PRÉ-PANDEMIA}

O grupo PET realiza seu planejamento, geralmente, no início do ano, antecedendo o começo das atividades letivas. Dessa forma, são designados os integrantes de cada subprojeto, distribuindo os membros (voluntários e bolsistas) de forma que todos integrem um número equilibrado de subprojetos, para que por fim, as metas e objetivos do grupo sejam alcançados. Uma descrição mais detalhada de todos os projetos pode ser encontrada no documento de planejamento anual (PET UFES, 2020). 
Destaca-se a importância das atividades desenvolvidas pelo PET, uma vez que agregam na formação dos alunos à nível de graduação, os auxiliando a manterem-se sempre atualizados, tendo em vista as tecnologias em constante desenvolvimento e a necessidade de profissionais críticos e inovadores para a construção de uma sociedade mais sustentável (MEC/SESu, 2006).

O planejamento dos projetos para 2020 foi realizado sem conjecturar nenhum tipo de restrição física ou financeira, pois no início deste ano pouco se comentava sobre os riscos da COVID-19 no Brasil (ORTIZ, 2020). Nesse cenário, os subprojetos foram planejados normalmente de acordo com seus objetivos individuais. Destacamos alguns dos projetos nos itens a seguir.

\subsection{EmpreendoPET}

Este projeto tem como objetivo estimular e desenvolver o espírito empreendedor nos alunos, não somente membros do PET mas, de todos os cursos de engenharia da UFES, dada a importância de assuntos transversais no ensino universitário, principalmente em contextos de crise (BARBA-SÁNCHEZ, 2018).

Rodas de conversa entre os alunos dos cursos de Engenharia a respeito das habilidades necessárias para o sucesso de um profissional empreendedor e o Circuito de Empreendedorismo do PET (CEPET), contendo palestras e eventos com profissionais empreendedores estavam elencadas no planejamento, todas estas a fim de proporcionar uma vantajosa troca de experiências, expandindo o conhecimento dos alunos sobre questões envolvendo o tema.

\subsection{Minicursos}

Em geral, os minicursos são elaborados e ministrados de acordo com a demanda do colegiado do curso e dos discentes, sempre alinhados ao mercado de trabalho. Projetos como este são de grande importância para diminuir a reprovação, evasão e retenção na Engenharia Elétrica.

Para 2020, os minicursos previstos eram de introdução a VBA e Matlab avançado. O VBA (acrônimo de Visual Basic for Applications) é uma ferramenta da Microsoft muito importante na engenharia, pois permite ao usuário aplicar recursos de programação para o gerenciamento de pastas de trabalho e planilhas, aplicando diversos recursos e permitindo uma gama de aplicações (MICROSOFT, 2019). O Matlab é um software para simulações numéricas utilizado por milhões de profissionais ao redor do mundo, podendo ser utilizado em vários domínios como: Análise de Dados, Controle, Inteligência Artificial, Fotônica, Sistemas de Comunicação etc. (MATHWORKS, 2020). Estes são recursos indispensáveis para a realização de muitas unidades curriculares do curso.

\subsection{Saúde PET}

O Saúde PET foi desenvolvido com o objetivo de prezar pela saúde mental dos membros, com a realização de atividades para melhorar a integração dos participantes do programa e dessa forma amenizar a demanda física e mental exigida pelo curso com momentos de descontração.

Para tanto, eram planejados encontros fora do ambiente universitário para atividades diversas de lazer entre os membros e o professor tutor. 


\subsection{Visitas Técnicas}

O projeto Visitas Técnicas é responsável por fomentar a relação universidadeindústria. Os integrantes organizam visitas técnicas em empresas da área de tecnologia e engenharia no intuito de gerar conhecimento fora da universidade, além de ampliar a rede de contatos entre a academia e o mercado de trabalho, estreitando laços com o mercado de trabalho e, consequentemente, permitindo aos alunos maior entendimento da tecnologia e inovação no estado.

Os eventos realizados anteriormente contavam sempre com a presença de um profissional responsável (geralmente, um engenheiro eletricista) que conduzia os participantes fornecendo informações técnicas pertinentes. Empresas locais como Vale e ArcelorMittal, têm tido participação ativa na formação dos estudantes do curso, permitindo que os alunos conheçam as suas instalações, bem como realizando parcerias com a instituição.

No cenário pré-pandemia, era planejada a organização de eventos presenciais em diversas empresas como a Vale do Rio Doce, Arcelormittal e EDP, objetivando maior proximidade e conhecimento da indústria capixaba.

\section{$2.5 \quad$ LINK}

O LINK surgiu como uma ferramenta de divulgação para os estudantes da graduação, compartilhando eventos, processos seletivos de estágio, atividades extracurriculares e atividades de pesquisa, ensino e extensão, visto a pouca visibilidade da maioria dessas oportunidades em meio aos alunos de graduação.

Planejava-se realizar postagens conforme descrito acima, além de outros conteúdos pertinentes à graduação, buscando uma frequência de postagens e agilidade para a divulgação, principalmente, das oportunidades de emprego e estágio, devido aos períodos de inscrição para os processos seletivos serem curtos.

\subsection{Visitas ao Ensino Médio}

O projeto Visitas ao Ensino Médio tinha como principal objetivo estreitar a relação entre os alunos da rede pública de ensino da cidade de Vitória e a Universidade, mais especificamente aproximando-os ao curso de Engenharia Elétrica.

Conjecturava-se fomentar o interesse dos jovens de ensino médio através de uma exposição mais lúdica e interativa do curso de Engenharia Elétrica ministrado na UFES, bem como por intermédio de debates, a fim de desmistificar perante a sociedade a universidade pública brasileira.

\section{A TECNOLOGIA COMO ALIADA NA ADAPTAÇÃO DOS SUBPROJETOS AO CONTEXTO PANDÊMICO}

Com a suspensão das atividades presenciais pela UFES devido ao surto de COVID19 no estado do Espírito Santo, o andamento de todo o planejamento do PET Elétrica foi extremamente prejudicado pois, como a maior parte dos projetos ativos eram realizados no formato presencial dentro das dependências da universidade, não havia, até então, uma noção formada de como continuar com a execução dos mesmos. Em sua maior parte, atividades voltadas para palestras e encontros como o Empreendo PET, Saúde PET e Visitas Técnicas foram completamente suspensas, ficando inativas por alguns meses. 
Quanto a projetos voltados para execução de reuniões, elaboração e aplicação de minicursos, uma transição para o mundo virtual acabou ocorrendo de forma natural pela facilidade encontrada na utilização de aplicativos e softwares como o Whatsapp, Telegram e Discord para a realização destas atividades.

\subsection{EmpreendoPET}

O Empreendo PET foi um dos projetos que viu na adesão ao evento de formato online uma solução muito eficaz. Para tanto, foi idealizada a realização de lives com convidados para discutir as inovações do mercado empreendedor no recente cenário epidêmico (PET ELÉTRICA, 2020).

\subsection{Minicursos}

De modo geral os materiais para aplicação dos minicursos sempre foram planejados para uma aplicação presencial. Porém, com a falta de previsão de término da pandemia, tornou-se necessário um remodelamento dos cursos para um formato online, sendo necessário remodelar o material de estudo com o intuito que este se adequasse ao novo formato. Além disso, o grupo precisou se capacitar na edição de vídeos para publicação de aulas. Algumas vantagens foram propiciadas pela modalidade remota, como por exemplo a possibilidade de acesso à gravação das aulas em horário posterior ao encontro ao vivo, permitindo haver um alcance maior das aulas. Como desvantagem, a redução na interação dos petianos com os alunos para tirarem dúvidas relacionadas aos exercícios ministrados.

\subsection{SaúdePET}

Com o auxílio da plataforma Discord o Saúde PET conseguiu realizar eventos de forma a proporcionar momentos de lazer e descontração aos membros do PET Elétrica durante o período de pandemia. Entre estes eventos haviam a "Noite de Filme" e a "Noite de jogos", ambas realizadas de forma online.

O projeto passou também a abranger a saúde mental dos alunos do curso, onde eram promovidas rodas de conversa com o tema de prevenção ao suicídio, além de divulgar, por publicações nas redes sociais, assuntos sobre temas referentes à saúde mental dos alunos do curso de Engenharia Elétrica.

\subsection{Visitas Técnicas}

A principal e mais pertinente mudança foi no que diz respeito ao modelo de visitas presenciais para visitas online onde os membros do grupo iam até o local, acompanhados de um engenheiro ou o responsável da área, e realizavam uma filmagem abordando pontos técnicos relevantes para os alunos do curso de Engenharia Elétrica.

Outra solução foi a realização de encontros e bate-papos virtuais com profissionais para tratar sobre diversos assuntos de cunho técnico. Nesse sentido, foi possível realizar duas visitas e uma apresentação que tiveram como temas: a visita a uma instalação de uma usina de microgeração de energia com a fonte solar; uma conversa sobre o futuro mercadológico da geração distribuída no Brasil; e uma visita a uma estação de antena e rádio no bairro da Fonte Grande, em Vitória.

\subsection{LINK}


Se tratando de um projeto realizado através das redes sociais, foi possível dar prosseguimento às atividades. No entanto, houve um prejuízo decorrente do número reduzido de oportunidades, resultado dos reflexos da pandemia no mercado de trabalho. Os focos do projeto eram os processos seletivos de estágio e atividades de extensão. Sendo assim, o LINK teve de ser adaptado, passando a divulgar, majoritariamente, cursos/palestras online e webinários.

\subsection{Visitas ao Ensino Médio}

O projeto de Visitas ao Ensino Médio não pôde ser adaptado para um formato virtual. Tendo em consideração o objetivo do projeto de estreitar os laços entre a UFES e as instituições de ensino público de Vitória, os eventos programados não puderam ser concretizados pois as escolas públicas tiveram suas atividades interrompidas. Outro fator que impediu a adaptação do projeto foi o perfil heterogêneo das instituições, acarretando um possível prejuízo para alguns estudantes que não poderiam ter acesso aos eventos em formato virtual.

O Quadro 1 apresenta o resumo de alguns projetos contidos no planejamento inicial do grupo e sua principal adaptação no contexto da pandemia. Além disso, o relatório anual contém a descrição do desenvolvimento de todos os projetos durante a pandemia (PET, 2020)

Quadro 1 - Quadro resumo descrevendo alguns projetos ativos do PET Elétrica durante contexto prépandêmico e as alterações necessárias devido a pandemia.

\begin{tabular}{|c|l|l|l|l|}
\hline $\begin{array}{c}\text { Nome do } \\
\text { Projeto }\end{array}$ & \multicolumn{1}{|c|}{ Objetivos } & Participantes & $\begin{array}{l}\text { Público- } \\
\text { alvo }\end{array}$ & \multicolumn{1}{c|}{ Adaptação } \\
\hline EmpreendoPET & $\begin{array}{l}\text { Inserir os discentes no } \\
\text { campo do } \\
\text { empreendedorismo. }\end{array}$ & $\begin{array}{l}\text { Petianos e } \\
\text { empreendedores } \\
\text { locais renomados. }\end{array}$ & $\begin{array}{l}\text { Discentes } \\
\text { do curso. }\end{array}$ & $\begin{array}{l}\text { Organização de } \\
\text { lives. }\end{array}$ \\
\hline Minicursos & $\begin{array}{l}\text { Promover a capacitação dos } \\
\text { discentes; diminuir } \\
\text { reprovação, evasão e } \\
\text { retenção. }\end{array}$ & Petianos. & $\begin{array}{l}\text { Discentes } \\
\text { do curso. }\end{array}$ & $\begin{array}{l}\text { Cursos on-line } \\
\text { em salas do } \\
\text { Google } \\
\text { Classroom. }\end{array}$ \\
\hline Saúde PET & $\begin{array}{l}\text { Proporcionar um espaço em } \\
\text { que os membros do grupo } \\
\text { possam cuidar do seu bem } \\
\text { estar mental. }\end{array}$ & Petianos. & $\begin{array}{l}\text { Petianos } \\
\text { do grupo. }\end{array}$ & $\begin{array}{l}\text { Roda de } \\
\text { conversa online e } \\
\text { integração } \\
\text { remota. }\end{array}$ \\
\hline
\end{tabular}




\begin{tabular}{|c|l|l|l|l|}
\hline Visitas Técnicas & $\begin{array}{l}\text { Fomentar a interação } \\
\text { universidade-indústria. }\end{array}$ & $\begin{array}{l}\text { Petianos e } \\
\text { empresas locais. }\end{array}$ & $\begin{array}{l}\text { Discentes } \\
\text { do curso. }\end{array}$ & $\begin{array}{l}\text { Visitas } \\
\text { individuais } \\
\text { gravadas. }\end{array}$ \\
\hline LINK & $\begin{array}{l}\text { Divulgar informações } \\
\text { relevantes aos alunos do } \\
\text { curso. }\end{array}$ & Petianos. & $\begin{array}{l}\text { Discentes } \\
\text { do curso. }\end{array}$ & $\begin{array}{l}\text { Restrito apenas a } \\
\text { divulgação por } \\
\text { meio das redes } \\
\text { sociais. }\end{array}$ \\
Ensitas ao & $\begin{array}{l}\text { Passar informações e } \\
\text { experiências pessoais a } \\
\text { alunos de nível médio sobre } \\
\text { o curso de Engenharia } \\
\text { Elétrica }\end{array}$ & Petianos. & $\begin{array}{l}\text { Alunos da } \\
\text { rede } \\
\text { pública. }\end{array}$ & $\begin{array}{l}\text { Não foi possível } \\
\text { adaptar. }\end{array}$ \\
\hline
\end{tabular}

Fonte: Próprios autores.

\section{RESULTADOS}

O processo de adaptação do grupo à realização dos subprojetos em formato virtual, consequência da interrupção das atividades acadêmicas presenciais, mostrou-se um grande desafio. Algumas atividades precisaram ser totalmente repensadas, necessitando uma mudança drástica nas metas propostas no planejamento e exigindo dos membros do grupo PET Elétrica o exercício da criatividade e inovação para contornar os problemas advindos da mudança repentina no cotidiano universitário. Outros subprojetos puderam ser realizados em sua plenitude ou de forma muito semelhante à proposta inicial. Em ambos os casos, as ferramentas digitais foram as principais aliadas para o prosseguimento das atividades.

Pretendendo obter um feedback objetivo a respeito da adoção das ferramentas digitais no cotidiano do grupo, foram levantados alguns questionamentos junto aos membros e ex-membros que estiveram presentes no processo de transição do presencial para o virtual, como segue:

- Quanto as ferramentas digitais impactaram positivamente a adaptação das atividades em que você teve participação?

- Você acredita que em um contexto pós-pandemia, em uma possível volta das atividades presenciais, as adaptações feitas poderão ser mantidas?

- Quais adaptações devem permanecer pós-pandemia?

- $\mathrm{Na}$ sua opinião, quanto as atividades foram prejudicadas pela interrupção das atividades presenciais?

- As atividades que você desenvolveu foram cumpridas em formato virtual?

$\mathrm{Na}$ segunda questão, foram dadas três opções: Sim, todas as adaptações; Sim, algumas adaptações; Não, nenhuma adaptação. Na terceira questão, foram citadas três mudanças implementadas: Reuniões virtuais entre os grupos de subprojetos; Reuniões Administrativas em formato virtual; Utilização do Telegram para votações. Além dessas três opções, havia a opção "Outros", cabendo ao respondente descrever sua resposta, nesse 
caso. As demais questões foram avaliadas numa escala de 1 a 10 , sendo 1 pouco/não cumpridas e 10 muito/totalmente cumpridas.

Dos 14 membros presentes no processo de transição, 12 responderam ao levantamento. Destes, $50 \%$ avaliaram o impacto da utilização de ferramentas digitais como WhatsApp, Discord, Google Teams e Microsoft Teams, como muito positivo (classificação máxima). Outros $41,7 \%$ também avaliaram positivamente, porém, atribuindo nota 8 à mudança, como pode ser observado na Figura 1 abaixo:

\title{
Figura 1 - Histograma do impacto positivo das
} ferramentas digitais nas atividades.

\begin{abstract}
Quanto as ferramentas digitais como: aplicativos (WhatsApp, Discord, Google Meet, Microsoft Teams), notebook, celular, desktop, impactaram p...ão das atividades em que você teve participação? 12 respostas
\end{abstract}

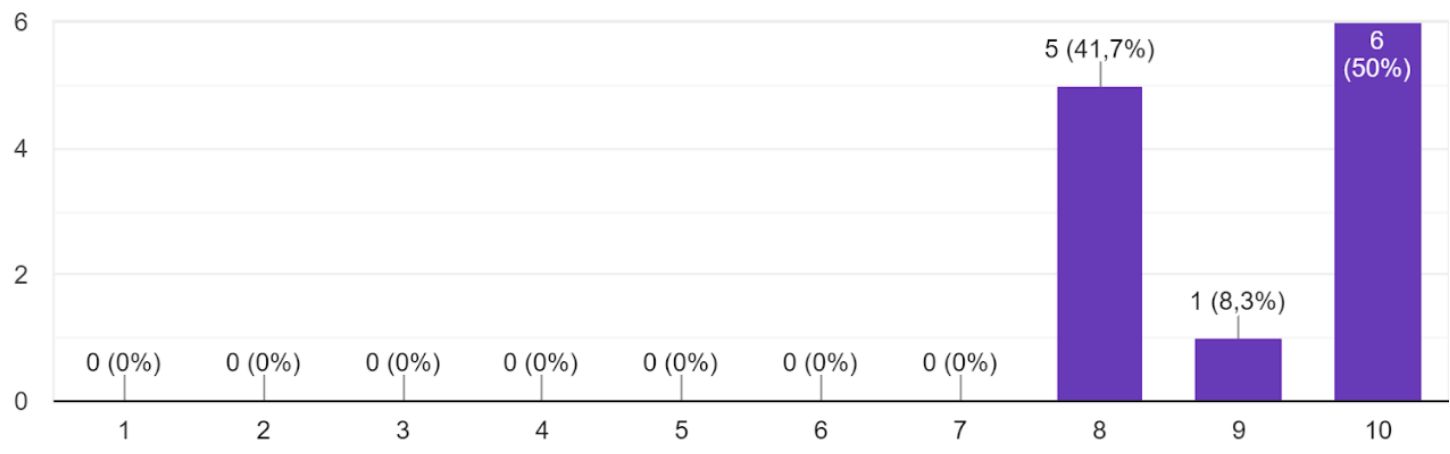

Fonte: Próprios autores.

Quando perguntados sobre quais adaptações deveriam perdurar pós-pandemia, $75 \%$ dos participantes apontaram que as reuniões virtuais entre os grupos dos subprojetos deveriam permanecer nesse formato. Outros $8,3 \%$ apontaram as reuniões administrativas em formato virtual, demonstrando uma certa preferência pelas reuniões administrativas em caráter presencial. Por fim, 83,3\% mostraram-se favoráveis a utilização do aplicativo Telegram para votações, futuramente. A Figura 2 ilustra as principais mudanças no ponto de vista dos membros do grupo.

Figura 2 - Gráfico das atividades que devem permanecer no seu novo formato de acordo com os membros. 
Quais adaptações abaixo devem permanecer pós-pandemia?

12 respostas

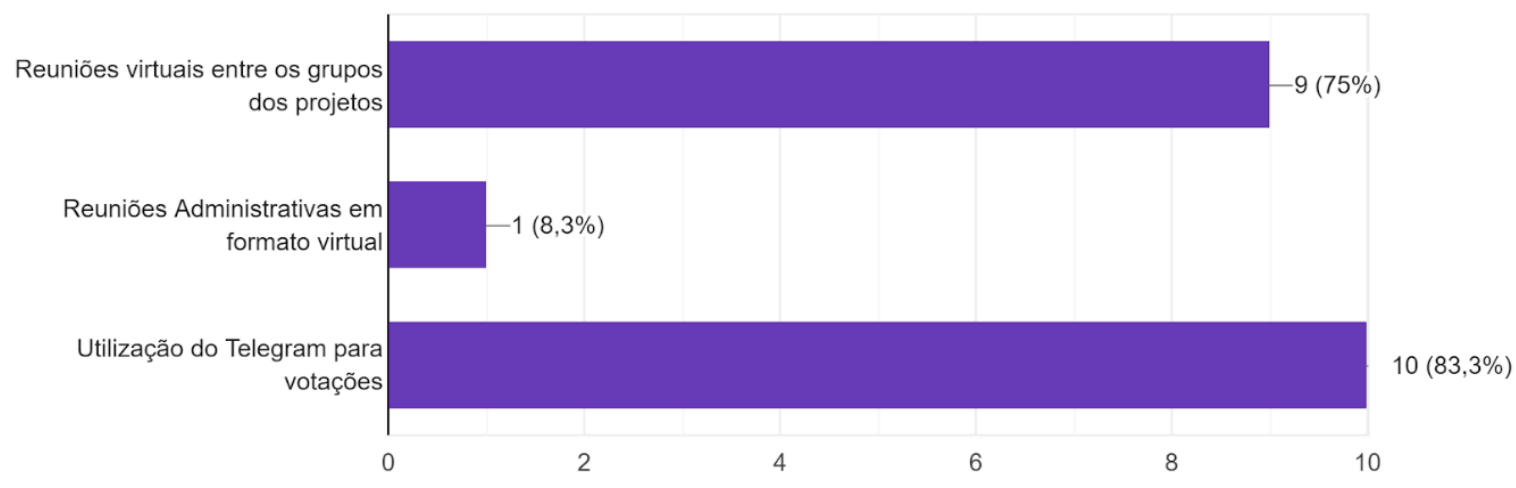

Fonte: Próprios autores.

Em relação ao prejuízo decorrente da interrupção das atividades presenciais $50 \%$ dos participantes indicaram um prejuízo médio (entre 4 e 6), 33,3\% um prejuízo considerável (entre 7 e 8) e 16,6\% afirmaram que suas atividades foram muito prejudicadas (classificações máximas). A Figura 3 ilustra esse panorama.

Figura 3 - Histograma do grau de prejuízo das atividades.

Na sua opinião, na escala abaixo, quanto as atividades foram prejudicadas pela interrupção das atividades presenciais?

12 respostas

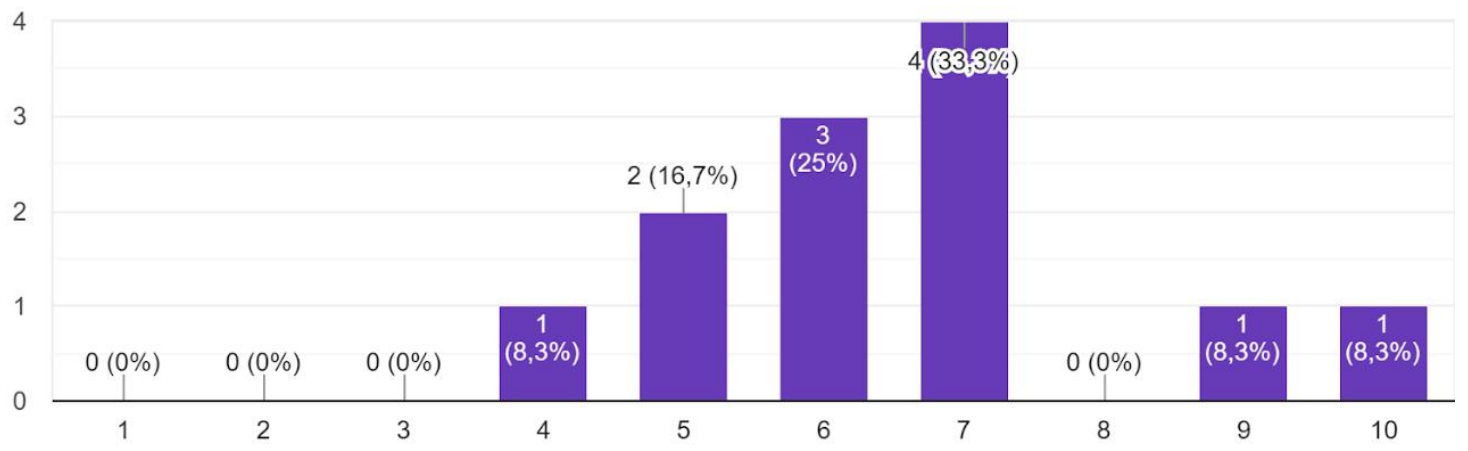

Fonte: Próprios autores.

Quando perguntados sobre o cumprimento das atividades, nenhum dos questionados indicou ter cumprido totalmente (classificação máxima) o planejamento inicial. A Figura 4 mostra a realidade retratada neste trabalho, na qual alguns subprojetos foram mais afetados enquanto outros puderam ser realizados de forma muito semelhante à planejada. 
Figura 4 - Histograma do grau de Cumprimento das atividades em formato virtual tendo em vista o

planejamento inicial.

\begin{abstract}
As atividades que você desenvolveu foram cumpridas em formato virtual?
12 respostas
\end{abstract}

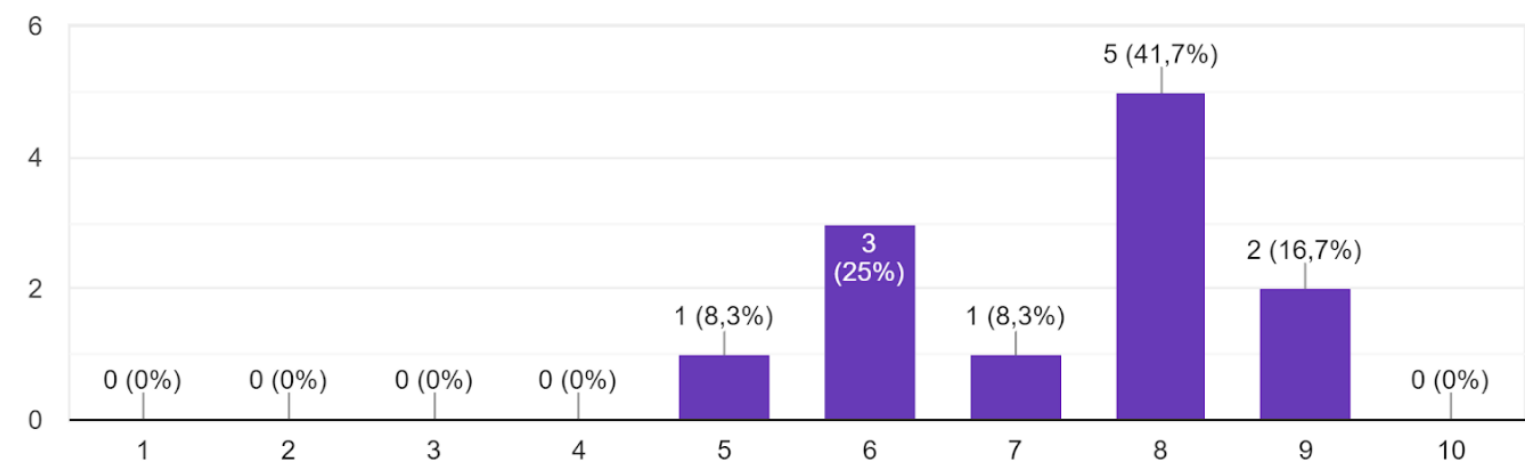

Fonte: Próprios autores.

Por fim, todos os participantes demonstraram o desejo de manter algumas das adaptações em um possível cenário de volta das atividades presenciais.

\title{
5 CONSIDERAÇÕES FINAIS
}

Sabe-se que, atualmente, o PET compõe um instrumento de inclusão na educação pública brasileira, por conseguinte, a adaptação do programa ao formato virtual tornou-se uma prioridade tendo em conta a situação financeira delicada de alguns membros bolsistas que necessitam desse instrumento para a manutenção de seus estudos. Desse modo, os resultados expostos neste trabalho ganham ainda mais importância.

Observando tais resultados é possível notar que a paralisação das atividades presenciais ocasionou um intenso impacto na rotina de trabalho do grupo PET Engenharia Elétrica. No entanto, as ferramentas digitais configuraram um importante instrumento a favor do processo de adaptação dos projetos.

Segundo a avaliação dos próprios membros, notou-se certo prejuízo em decorrência da mudança repentina, porém, é possível observar, por meio da Figura 3, que o impacto negativo dessas mudanças não foi tão intenso como se era esperado no momento do anúncio da suspensão das atividades em caráter presencial. Podemos atribuir a atenuação desse impacto às ferramentas digitais. Graças a elas foi possível a concretização de reuniões formais e informais e desenvolvimento de eventos. Em alguns casos, pode-se afirmar que as tecnologias permitiram um alcance ainda maior no que se refere ao contato com profissionais de diversos ramos para participação nos eventos do grupo e a divulgação dos mesmos para a comunidade acadêmica e externa.

Nessa conjuntura, as tecnologias ampliaram o horizonte de opções do grupo, propiciando a potencialização de alguns subprojetos. De fato, alguns projetos não se beneficiaram dessa mudança, mas os resultados aqui abordados mostram que em um cenário futuro, muitas das adaptações aplicadas e ferramentas digitais empregadas continuarão presentes no cotidiano. 
A pandemia trouxe diversos problemas para a nossa sociedade e escancarou a desigualdade social vivida pela população brasileira. Contudo, se for possível absorver pontos positivos dessa crise, o emprego das ferramentas digitais nas mais diversas esferas de trabalho, com certeza será um deles.

\section{Agradecimentos}

Agradecemos ao MEC e ao FNDE pelo apoio estrutural e financeiro que possibilitou a manutenção das atividades do grupo PET Engenharia Elétrica em formato virtual.

\section{REFERÊNCIAS}

BARBA-SÁNCHEZ, Virginia et ATIENZA-SAHUQUILLO, Carlos. Entrepreneurial intention among engineering students: The role of entrepreneurship education. European Research on Management and Business Economics, v. 24, n. 1, p. 53-61, 2018.

CONSELHO UNIVERSITÁRIO DA UNIVERSIDADE FEDERAL DO ESPÍRITO SANTO. Processo Digital no 017402/2020-16 - GABINETE DA REITORIA, de 16 de março de 2020: Suspensão das atividades na Ufes. Vitória, 2020.

CHAVES, Eduardo O. C. Tecnologias na educação. Disponível em: https://smeduquedecaxias.ri.gov.br/nead/Biblioteca/Forma\%C3\%A7\%C3\%A30\%20Contin uada/Tecnologia/chaves-tecnologia.pdf. Acesso em: 23 abr. 2021.

DIÁRIO OFICIAL DO ESPÍRITO SANTO. Decreto № 4593-R, de 13 de março de 2020: decreta o estado de emergência em saúde pública no Estado do Espírito Santo e estabelece medidas sanitárias e administrativas para prevenção, controle e contenção de riscos, danos e agravos decorrentes do surto de coronavírus (COVID-19) e dá outras providências. Vitória, 2020.

Decreto № 4597-R, de 16 de março de 2020: dispõe sobre as medidas para enfrentamento da emergência de saúde pública decorrente do coronavírus (COVID-19) na área da educação, e dá outras providências. Vitória, 2020.

MATHWORKS: Matlab. Disponível em: https://www.mathworks.com/products/matlab.html. Acesso em: 07 mai. 2021.

MICROSOFT; MICROSOFT DOCS. Introdução ao VBA no Office. Disponível em: https://docs.microsoft.com/pt-br/office/vba/library-reference/concepts/getting-started-withvba-in-office. Acesso em: 23 abr. 2021.

MINISTÉRIO DA EDUCAÇÃO; INSTITUTO NACIONAL DE ESTUDOS E PESQUISAS EDUCACIONAIS ANÍSIO TEIXEIRA. Ensino a distância se confirma como tendência. Disponível em: http://www.gov.br/inep/pt-br/assuntos/noticias/censo-da-educacaosuperior/ensino-a-distancia-se-confirma-como-tendencia. Acesso em: 23 abr. 2020. 
MINISTÉRIO DA EDUCAÇÃO; SECRETARIA DE EDUCAÇÃO SUPERIOR. Programa de Educação Tutorial - PET - Manual de Orientações Básicas. Disponível em: https://portal.mec.gov.br/index.php?option=com docman\&view=download\&alias=338manualorientabasicas\&category slug=pet-programa-de-educacao-tutorial\&ltemid=30192. Acesso em: 23 abr. 2021.

PET ELÉTRICA; UFES. EmpreendoPET - 0 que são os 10 tipos de inovação digital ?. Disponível

em: https://www.youtube.com/watch?v=z766RcEX8dM\&ab channel=PETEl\%C3\%A9trica . Acesso em: 07 mai. 2021.

PROGRAMA DE EDUCAÇÃO TUTORIAL (PET); UFES. Planejamentos 2020. Disponível em:

https://pet.ufes.br/wparchives/Documentos/Planejamentos\%202020/Plan\%20Eng\%20Eletrica.pdf. Acesso em: 23 abr. 2021.

PROGRAMA DE EDUCAÇÃO TUTORIAL (PET); UFES. Relatório anual 2020. Disponível em: https://www.peteletrica.ufes.br/documentos/. Acesso em: 23 abr. 2021.

SILVEIRA, A. P. K. et al. Uma breve revisão histórica do papel das videoaulas na EaD no Brasil. Disponível em:

https://periodicos.ufsc.br/index.php/workingpapers/article/view/19848420.2010v11n2p53/17481. Acesso em: 23 abr. 2021.

ORTIZ, Brenda. Brasil continua com 9 casos suspeitos de coronavírus. G1, São Paulo, $302020 . \quad$ jan. Disponível em: https:/g1.globo.com/bemestar/coronavirus/noticia/2020/01/30/brasil-continua-com-9casos-suspeitos-de-coronavirus.ghtml. Acesso em: 23 abr. 2021.

\section{TECHNOLOGY AS AN ADAPTATION TOOL FOR THE TUTORIAL EDUCATION PROGRAM IN ELECTRICAL ENGINEERING IN THE CONTEXT OF THE PANDEMIC OF COVID-19}

Abstract: With the advent of the Covid-19 pandemic, social isolation became a rule, consequently, leading to the suspension of school activities in educational institutions. This article aims to perform an analysis of the impacts caused by the pandemic within the PET Electrical Engineering group of the Federal University of Espirito Santo and, mainly, the adaptations adopted by the members in order to circumvent this situation with the help of technology. For this, a balance of the projects executed by PET Electrical Engineering in the pandemic and pre-pandemic contexts was prepared, in addition to data collection with the group members in order to conduct a quali-quantitative survey regarding the changes adopted. Finally, the results of this survey were discussed at the end of the article in order to display the benefits of technology in this situation.

Keywords: PET. Adaptation. Pandemic. Remote teaching. Innovation. 